\title{
Recombining ideas from art and cultural history museums in theory and practice
}

\author{
OUti TURPEINEN *
}

\begin{abstract}
This article is concerned with visual elements of exhibition design in cultural history museums and the way they produce meanings. The aim is to open up and analyze the process of constructing meanings from a visual point of view. Examples are chosen from the authors own artistic museum installations, which act as test spaces in the research. Cultural history museums can act as a treasure box for artistic work, and vice versa, contemporary art and design can give valuable tools for display habits in cultural history museums.
\end{abstract}

Keywords: Exhibition design, atmosphere, museum meanings, artistic practices.

Museums were in deep crisis at the beginning of the 1990s, when the meanings associated with the museum objects did not correspond with the newly posed analytical questions of what is presented in museums, whose history it represents and from what perspective (Corrin 1994: 1, Karp 1996: 265). Consequently, as a research target, museums have been examined from several viewpoints, including the pedagogical, the historical and the ideological. However, in the case of cultural history museums, often these viewpoints do not take into account the question of visuality. Therefore, the approach in this article is formed on the basis of my background education as an artist and a designer. I will give a brief insight into some aspects of my own DA (Doctor of Arts) research (Turpeinen 2005A), which is particu- larly concerned with the visual aspects of museum exhibitions. The research focuses on how meanings are constructed for the purposes of exhibition design in cultural history museums. In other words, how does visuality in exhibition design affect the interpretation? How are meanings constructed in cultural history museum exhibitions? How are meanings represented as visual signs by the exhibition design?

In my research, I question the objective approach adopted by modern museums, which assumes that the perception of knowledge is unified and transferable (Hooper-Greenhill 2000: 127). Typically, modern museums aim towards "truth" (Aurasmaa 2002: 28). In contrast, I am interested in an open subjective approach, where there are possibilities for multi- 
84 ple interpretations of the exhibited objects and where this approach is encouraged by the exhibition design. Museum artefacts are not always exhibited in the same way, nor does their interpretation remain unchanged. Thus, the associated meanings are linked to the context as well as the time, place and culture and to the physical exhibition space. In this article, I aim to give some insight into these topics.

This interpretation process is semiotic in nature. This is why I have adopted philosopher Charles Sanders Peirce's (1839-1914) concept of the sign as one theoretical starting point for my research. ${ }^{1}$ The concept of the sign is central to Peircean theory. The sign is seen as a triadic model, with subtypes of symbols, indices and icons. From this semiotic point of view, interpretation is seen as a thought process where meanings are in constant movement - in other words, meanings are not fixed. When this is applied to researching exhibition design, it is possible to acknowledge a meaning construction which is actually a physical and visual structure, where the artefacts are always displayed in a particular context.

\section{ARGUMENTS BETWEEN CONTEMPORARY ARTS AND CULTURAL HISTORY MUSEUMS}

To be able to research how meanings are introduced into exhibition design, I have chosen to look at the relationship between contemporary art and cultural history museums. They have a common history in the concept of the curiosity cabinet, but have been largely separated in the 20th century. Still, artists have used the museum as their inspiration or a place where to question the prevailing meanings. For example, exhibitions where artistic and museological practices have intertwined have attracted interest. Exhibitions like the $\mathrm{Mu}$ seum as Muse. Artists Reflect at MoMA, New York, 1999; Give\&Take at the V\&A, London, 2001; or the Afro-American artist Fred Wilson's installation Site Unseen: Dwellings of the Demons at the Museum of World Cultures, Gothenburg, Sweden 2004 propose new contexts for the exhibited artefacts. Artistic practices in cultural history museums can create new meanings for the artefacts in a museum context. ${ }^{2}$ This creates one interesting track, or possible route, for the 21 st century museum, to which I will refer regularly in this article.

The use of artistic practices in cultural history museums reflects well with the British museology researcher Eilean Hooper-Greenhill's notion concerning the new concept of "postmuseum", where the museum concentrates on the use of museum objects, rather than further accumulation (Hooper-Greenhill 2000: 152153). The approach I adopt in my research can be seen as supporting her view. There seems to be a clear functional use for conceptual artistic installations in cultural history museums, which can confer new associations and meanings on exhibition artefacts. After all, the creation of something new has been a characteristic of art since romanticism (Aurasmaa 2002: 335). On the other hand, cultural history museums often focus on conserving the cultural heritage. One might ask, however, whether the purpose of cultural history museums is to encourage the image of a dusty and old-fashioned museum, which does not connect with contemporary life? The problematics that I pose seem to present a conflict between the grounding ideologies of art and those of cultural history museums: is the purpose to create something new or to conserve the old? 


\section{ALTERNATIVE INTERPRETATIONS}

The Finnish historical researcher Jorma Kalela's notion of stereotypical historical research also applies to the context of museum exhibitions. His question "What is relevant in history?" 3 is valuable, as it brings to the fore a critical approach to history and the presentation of history. To represent artefacts in museum exhibitions requires thorough examination of the selected narrative from various different perspectives, in order to avoid repeating in the museum exhibition clichés from the past or presenting a stale or stereotypical exhibition. Such an approach allows us to view history from multiple and varied perspectives and thus create updated interpretations.

Interpretation also changes in time and is hermeneutic in nature. ${ }^{4}$ Each visitor has his/her own background education, culture and situation, which affects the interpretation process. Therefore, one of my main research arguments is that museums cannot have a single goal in their exhibition design, even though the story of the exhibition might suggest certain meanings. If we thought an exhibition design were likened to a metaphor, it would not be important to aim for a single interpretation. Visual metaphors allow different interpretations from different people (Vihma 1995: 87). This kind of thinking can be applied both generally to exhibition design in cultural history museums and specifically to the fictive museum installations I have made as part of the research. The working methods of contemporary art, in particular, support the creation of multiple interpretations. This kind of thinking is not, however, often encouraged in cultural history museums. Art is often connected with emotions, whereas historical texts, for instance, relate to academic knowledge. Consequently, both inevitably change with time and they do have the possibility to work together in order to create atmospheres and experimental knowledge.

In my research, I have concluded that combining contemporary arts and cultural history knowledge and artefacts can confer new meanings to exhibition design. New meanings also create a new kind of knowledge. This can be seen in visual signs, in other words, in the interpretation of actual physical visual elements, such as colour, light, materials or artefacts placements. The presentation and seeking of new knowledge, for example in the form of contemporary art, gives us the opportunity to update the information the museum is giving. In the following, I will give some examples of this new knowledge, which I would also like to define as experiential knowledges, as it is strongly based on the experience gained in mounting the exhibitions from the visual and artistic perspective.

I will summarise the methods I have used in my research, as they might differ from the methods more commonly used in museological research. The methods I used included interdisciplinary methodologies, such as observing existing museum exhibitions (experiencing), making of exhibitions (making) and linking this knowledge with relevant museum history and theory (reading). The methods I have used - reading, experiencing and making - form an interdisciplinary approach. ${ }^{6}$ Together they also involve a new way of analysing meanings in exhibition design. For example, I have gained knowledge and ideas from my museum visits and from the theoretical literature survey which I bring to my own artistic work, and conversely, the theoretical discussion in the thesis has been influenced by 
my artistic work. The aim was to open up and analyse the process of constructing meaning. One of the main results of the research is the realisation that knowledge about this process can influence decision-making in exhibition design and add new insights into the process of creating meanings for the exhibition.

\section{Series of INStallations as test spaces}

As I mentioned earlier, in addition to researching meanings proposed by cultural history museums or other artists, I also created and tested different contexts for museum artefacts in my DA research. I made concrete physical installations as part of the research process, thus actively taking part in the object of my research rather than examining it solely from the outside. This kind of approach is a component of practice-based research, which is applied in art and design research work.

I made three fictive museum installations as part of my dissertation. They acted as test spaces for the research on the interpretation of museum objects. These installations were "Imprisoned Setting" (2000) at the Design Museum, Helsinki, "Memories from a Curiosity Cabinet" (2001) at the Vantaa Art Museum and "A British Noblewoman's Collection from 19th Century India” (2003) at Kiasma Museum of Contemporary Art, Helsinki. Through these test spaces, I was able to approach the questions of visual semantics in a concrete physical space and location. In a way, I imitated the way in which authentic cultural history museums work and combined this with the effect of my own visual way of making art.
THREE STARTING POINTS FOR THE PLANNING OF EXHIBITION DESIGN

The role of cultural history museums is often linked to transferring experiences from history and other cultures to the present time and place. One operating model is to evoke atmospheres and memories in the museum's visitors. But how are histories elicited to the exhibition visitors: as stories, text, sounds or maybe interactive workshops? Different ways of working can evoke different meanings, and exhibition designers need to be aware of this.

Constructing the exhibition design is primarily about communication. There is something that needs to be transferred to the visitors, a message. In my research, I conclude that there are three main ways to start planning an exhibition. The three different methods represent different ways to communicate the intended message. The first starting approach involves a specific museum collection which acts as the starting point for an exhibition. The exhibition is built around a collection, and furthermore the meanings relate to that specific context. Often a narrative is connected to this approach at a later stage. There are often many varying narratives to be found in a particular collection, depending on the perspective of the exhibition maker. With updated historical research, new meanings can be found in existing collections. This is also an area where artists have produced new interpretations of the past and suggested different visual meanings for the artefacts. ${ }^{7}$

The second starting approach is when a narrative is added to the exhibition script. ${ }^{8}$ With the narrative, the visitor is given the first information about the content of the exhibition. This narrative can be ideally seen in all visual material relating to the exhibition, and 


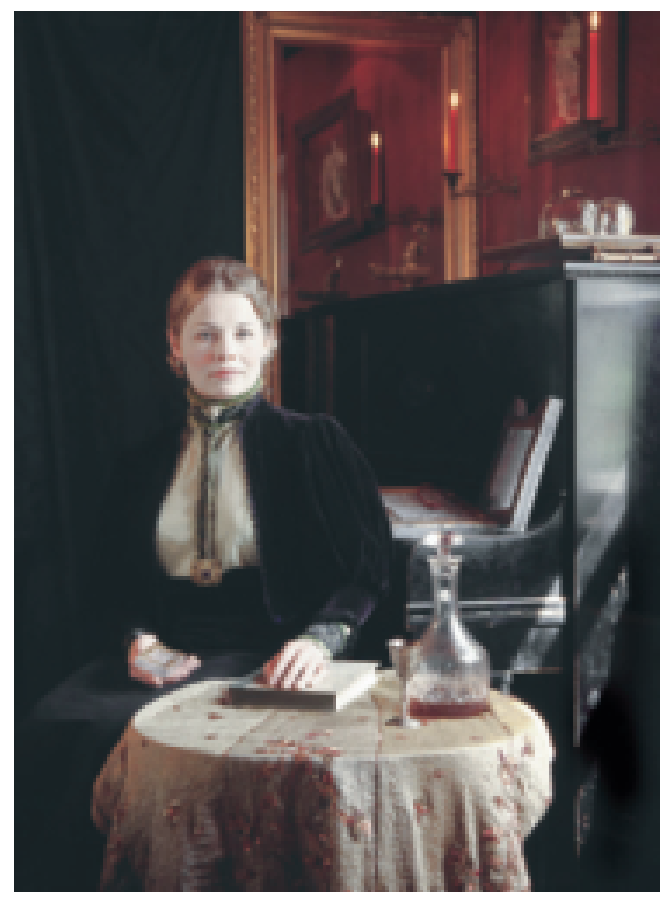

Fig. 1. The portrait of a fictive collector, Lady Helen Mary Frog from the fictive museum installation by Outi Turpeinen "British Noblewoman's Collection from 19th-Century India". The exhibition was shown in the Museum of Contemporary Art, Kiasma, Helsinki in 2003. Photo: Minna Kurjenluoma and Outi Turpeinen, actress: Tuula Niiranen.

this connects the narratives of exhibition design also to other narratives used in our time, like, for example brand management in business. Stories can also tune the visitors to the exhibition even before they even enter the exhibition space, in the form of advertisements or written criticisms. This can strongly affect the process of interpreting the exhibition before even entering the actual exhibition space.

In the image (fig. 1), you can see one example of a narrative, which I created for my own fictive museum installation. The portrait of the fictional collector, Lady Helen Mary Frog, was created to communicate the fictive narrative of the British Noblewoman's Collection from 19th Century India. The story of this installation was based on my visit to museums in England and the British Library, and it continued prompted by my curiosity about women collectors in the 19th century. After doing research on the subject, ${ }^{10} \mathrm{I}$ created my own fictional character. This constituted the main story which I created for the fictive museum installation. The main purpose, however, was to study the creation of meanings in a spatial construction. In other words, how can we introduce meanings into exhibition design, using visual elements?

One of the main findings in my DA (Doctor of Arts) research was that meanings can be incorporated into exhibition design, not only with narratives or in a collection-based environment, but also with the concept of atmosphere. As a result, atmosphere acts as the third starting point for planning an exhibition. In other words, the meanings produced by exhibition design are influenced by two parallel notions, i.e. stories and atmosphere. These meanings are slightly different in nature. Stories, both fictional and factual, are often based on historical knowledge, which is communicated through exhibited artefacts and their placement in a spatial unit. These stories can also be communicated with words. In addition to stories, the spatial construction also creates a particular atmosphere, which is not so easily communicated by words. Rather, this section of meanings works on another level and is connected with memories, feelings and experiences. These various layers of knowledge exist at the same time in the exhibition. The meanings are constructed and communicated in this space. 
A museum exhibition is always mounted by someone with a particular world-view regardless of whether he/she is conscious of it or not. Historical artefacts exist in an exhibition, where stories and atmospheres are created around them. Stories and atmospheres are introduced into spaces. These spaces are produced with a variety of concrete and physical visual elements. The three-dimensional composition of visual elements like colour, light, form, photos, materials and positioning of exhibited artefacts influences the meanings produced by the space. In other words, producing a desired atmosphere is particularly connected with spatiality.

In this respect, an exhibition is always a spatial experience, which requires an embodied approach. In a museum visit, not only the eye is looking at the exhibition, but the whole body is interpreting the experience. ${ }^{11}$ In this experience, these three starting points, collection, stories and atmosphere, can be interpreted simultaneously; in other words, they can all also exist at the same time.

\section{EXHIBITIONS AS ATMOSPHERES}

The aspect of atmosphere in exhibition design in cultural history museums has not received very much attention in research text, although designers of exhibitions acknowledge its existence. In the end of this article, I wish to concentrate on the visual elements that bring atmosphere into exhibition design in cultural history museums. The aim is to clarify my point of recombining ideas from art and cultural history museums. The following examples will give some insight into the problematic of how do we create a particular atmosphere and, furthermore, how can we analyze it?
The story of an exhibition leads the visitor through the museum space. A three-dimensional space requires movement and observation from various perspectives to grasp the spatiality. Often a space can look completely different from the far end. When I visited existing museum exhibitions as part of my research process, I moved around in the space in order to find interesting points of view for making notes. In general, spatial constructions can lead the visitor's movement in a certain way and often in exhibitions there is even a suggested route for visitors. This movement in the museum space makes the experience possible. A visitor can also be encouraged to find alternative routes into the exhibition design, which create new associations to the theme of the exhibition. According to the German philosopher Gernot Böhme:

Atmosphere is a prototypical 'between' phenomenon. Atmospheres fill spaces; they emanate from things, constellation of things and person. The aesthetics of atmospheres shifts attention away from the 'what' something represents, to the 'how' something is present. (Böhme 1998: 112-115)

Atmosphere moves attention away from the real or fictive museum objects, and emphasises the overall exhibition design in the process of creating meaning. An exhibition designer can highlight the atmosphere of the exhibition design to influence the feelings of the visitor. This relates to an aesthetic experience. In Peircean sense an aesthetic experience is seen as immediate, unexplainable and non-intellectual unconscious experience. However, afterwards it is possible to separate the elements, which created this experience, and that is when we move to the semantic level of the analysis (Vihma 1998: 12). In my own artistic 
work, I use my own aesthetic experiences and transform them to my own fictive museum installations. Then I carry out a research analysis of the experiences in close interplay with museological theory and history.

In my research I have been particularly interested in how meanings are built and created through visual elements in exhibition design. These visual elements, such as vitrines (or glass-cases), colour or light, affect the interpretation of museum artefacts. In the following I will give brief examples on how to analyze visual elements produced into an exhibition space.

Colour AS A VISUAL ELEMENT IN EXHIBITION DESIGN

Colour is an important factor in creating atmosphere. Colours can create a strong context for the artefacts. A certain colour can act as a metaphor, which reminds the visitor of something similar. In the installation "A British Noblewoman's Collection from 19th Century In-

Fig. 2. A view to the "A British Noblewoman's Collection from 19th-Century India" (2003) installation, where red color acted in an important symbolical role to be associated with authority, but also with passion. Photo: Minna Kurjenluoma.

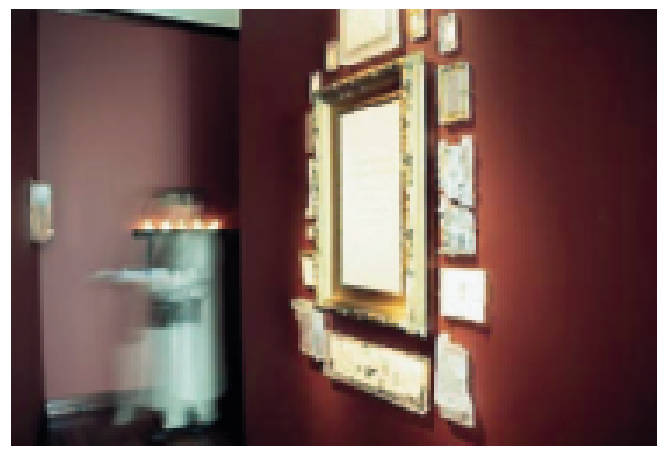

dia" (2003), the red colour can be interpreted as a symbol of power and authority, with links to imperialism, for instance. This connotation is strongly influenced by my visits to the British Museum in the early 1990s, with its strongly coloured walls. Red colour is also linked with passion, and passion as an emotion characterises a collector. A collector is passionate about his/her collection. For this installation, I also visited for example the Sir John Soane museum in London for inspiration on display techniques in the 19th century.

Another reason why I have also used strong colours in my own installations is to add contrast to the art museum context (fig. 2). By concentrating only on one colour installation I formed a unity in the space. Lady Frog's collection with 60 artefacts then added details to the walls. Artefacts always exist in a context, which affects the interpretation of them. The space I produced as an exhibition designer and researcher was iconic in relation to other cultural history museums, especially the ones I was visiting and reading about (similarity), but it simultaneously also created a contrast in relation to the art museum context.

Atmosphere is created primarily with contrast. The building where the exhibition is housed always lends certain meanings. Changes in atmosphere inside a building affect the context and thus shape the interpretation process. For example, all my fictive museum installations existed in a white cube, the art museum context. I wanted to bring historical feeling into this modernistic display arena, the white cube ${ }^{12}$. One reason for this was that I wanted to link the concept of museum back to its roots, back to the idea of curiosity cabinets, where art and artefacts had the opportunity to commingle for the purpose of giving insight to the represented world-view. 
This image (fig. 3) is from Kiasma, the $\mathrm{Mu}-$ seum of Contemporary Art, Helsinki where this installation was shown in 2003. In Finland, modernistic architecture has a fairly homogenous impact on atmosphere in art museums, with attributes such as clear-cut forms or logical use of natural materials (Ceferin 2004: 12). One of my main aims was to bring contrast into this notion of homogenous atmosphere.

\section{THE USE OF LIGHT IN EXHIBITION DESIGN}

The use of colour cannot be separated from the use of light. Also, different light sources have differing impacts on shades of colour. Especially with certain transparent materials, glass for example, light makes the qualities of glass visible, such as the levels of thickness or the surface structures. Light lifts the artefacts and makes them precious, in the same way as placing them in a vitrine does, for example. Shadow does not exist without light and in visual arts the interplay between light and sha-

Fig. 4. Outi Turpeinen, 2003 detail image of "The evolution rate of an Unknown Ritual Object I" (Compared to a Natural Creature) Cast and blown glass with fibre light and mixed media. Photo: Minna Kurjenluoma.

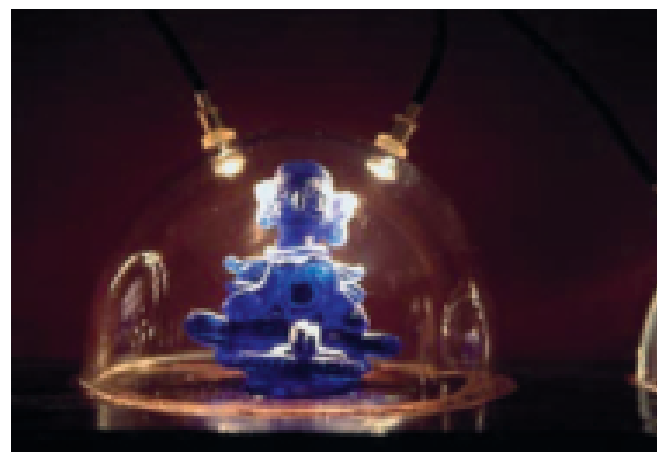

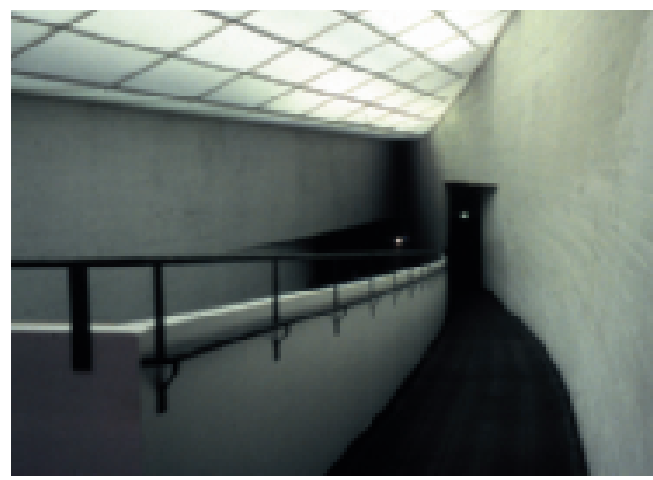

Fig. 3. The "A British Noblewoman's Collection from 19th-Century India" (2003) installation was shown in the Museum of Contemporary Arts, Helsinki, which has a Finnish character in its architecture (even though the building is designed by an American architect Steven Holl). Photo: Outi Turpeinen.

dow is used to separate what is relevant and what is not. This is highly applicable and also used in cultural history museum exhibitions.

In this image (fig. 4), from the same installation as all the previous images, I was interested in the connection between museum display techniques and laboratory practice, which had a connection in the 19th century and the same connection can also be seen in the works of some artists. ${ }^{13}$ Museums adapted operational models from laboratory forms in the 19th century (Forgan 1994). In contemporary art, the vitrine acts as a tool for representation. The glass of the vitrine forms both a surface and a space. The vitrine represents an artificial possibility to categorise chosen artefacts in a special way, where they are conceived as significant. In this work (fig. 4), I was also interested in breaking the concept of the vitrine by adding a fibre light directly to the vitrine. This interconnected the lighting, the vitrine and the artefact and did not leave them as visually 
separate elements. At first sight one might look quickly and not notice anything odd. Only after a closer look, can one start to wonder about the details and their connection to the story, the collection of the fictional collector, Lady Helen Mary Frog. This example shows how the use of artistic representation practices in exhibition design can give new associations to museum displays.

\section{MEANINGS ARE INTRODUCED INTO THE EXHI- BITION}

A vitrine with its contents together with the use of light and colour produces meanings. Similarly, an image (fig. 5) from the installation "A British Noblewomen's Collection from 19th century India” (a fictive museum installation) shows how an exhibition is always a constructed structure (built by someone) which is linked to its context. In this image specifically, an exhibition is always more or less a subjective interpretation which relates the world-view of the current time-period. With this installation, I primarily wanted to show the structure of an exhibition as a physical construction. It is this consciously built construction, which acts as a metaphor for an exhibition, which creates the meanings. All the visual details, light, colour, artefacts or vitrines create the context for the interpretation. Visual elements con be analyzed separately in a text (like for example in this text), but in a spatial context, they all affect each other and therefore also the interpretation.

The associations come from the spatial setting. It is possible to form and direct the visual elements in the space (e.g. light, colour, structures), yet it is not possible to fix meanings. In Peircean design semantics, the em- phasis is on constant movement of meanings between the sign and the interpreter. ${ }^{14}$ An exhibition as a whole acts as a sign, and it is an active producer of meanings. From the researched subject, in this case from spatial settings, the research analysis can produce experimental knowledge, based on the researchers own interpretation and previous knowledge. In other words, this knowledge is filtered through the researcher and it can vary according to the perspective of the researcher. As a result the experimental knowledge is also interpretative in nature.

The narratives of the exhibition tune the visitor to the atmosphere of the exhibition. The stories give viewers their first impression of the exhibition, often before entering the physical exhibition space (through other media like articles, websites or advertisements). However, only when the visitor enters the physical space is it possible to experience the spatial atmosphere. The visitor experience in a museum is embodied in nature, where informa-

Fig. 5. A view to the "A British Noblewoman's Collection from 19th-Century India" from the balcony, which shows the structures of the construction. The construction was built into a 10 meters high gallery space with three entrances. The image is taken from the balcony above the installation.

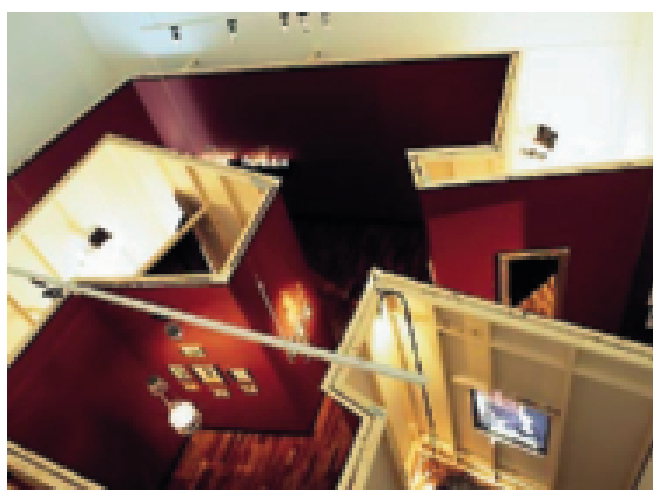


92 tion is received not only by the eyes, but also by the whole body.

\section{RECOMBINING ART AND CULTURAL HISTORY MUSEUMS}

Both in my art and in my research work, I am interested in recombining cultural history museums and art in terms of applying working methods from both of them. I believe this is one way to develop both. Cultural history museums can act as a treasure box for artistic work, and contemporary art and design can give valuable tools for display habits in cultural history museums. This interplay can provide new insight into the creation of meaning for artefacts in a context. This approach also adds value to the aspect of three-dimensional and visual experience as an alternative to an object-driven emphasis.

And finally, in this article I have given some insights into the use of artistic representation practices in exhibition design. The focus was on providing experiential knowledge and alternative ways of analyzing museum exhibitions. This kind of approach is also known as practice-led research, and it is connected to both process and communication. ${ }^{15}$ My viewpoint focuses attention on the visuality and conceptual thinking in cultural history museum displays. In this kind of approach, the aim is not a singular interpretation, neither an objective viewpoint. Rather, the purpose is to allow and encourage multiple interpretations which rely on personal feelings or memories, for example, and are connected with the concept of atmosphere. The mission of my research is also to encourage concepts of play and experiment in cultural history museums in order for them to stay alive.

\section{ACKNOWLEDGMENTS}

The DA (Doctor of Arts) research has been funded by the University of Art and Design, Helsinki (www.uiah.fi) and the writing of this article has been made possible with the funding of the SeFun (Semiotic Product Functions) Research Project (www.uiah.fi/sefun) financed by The Finnish Academy. I am grateful to both of them for funding my work. This article is a slightly modified version of an article I sent for The Museum conference (Leicester University 25.-27.4.2006) publication.

\section{NOtES}

1. For Peirce's philosophy, see for example Peirce (1893-1913) 1998 or

http://www.iupui.edu/-peirce/ep/ep2/ep2book/c h02/ep2ch2.htm, http://members.door.net/arisbe/arisbe.htm and http://plato.stanford.edu/entries/peirce/

2. For more, see Corrin 1994, 2001, McShine 1999 Putnam 2001 and Turpeinen 2005A.

3. Kalela 2000: 62-63.

4. By hermeneutic, I mean that the process of learning means gathering new knowledge on top of the old and always returning to the old in circles.

5. Experiential knowledge is a term linked to practice-based research. This term refers to knowledge based on artists' own experiences of the working process involved in producing works of art. The process also demands time. My own DA (Doctor of Arts) bresearch work took six years to complete. This might differ from the normal timeframe for a PhD in Britain, for example.

6. I discuss the methodologies more closely in the article "The interplay of art and research" (to be published in January 2007) in an anthology The Art of Research. Practice in Research of Art and De- 
sign ed. By Maarit Mäkelä and Sara Routarinne. Published by the University of Art and Design Helsinki (www.uiah.fi/publications). See also Turpeinen 2005B and Turpeinen 2005C.

7. The Afro-American artist, Fred Wilson is particularly well-known for his new interpretations on existing collections, like the "Mining the Museum" in Baltimore Historical Society, USA in 1994-2002 or "Site unseen: Dwellings of the demons" in The Museum of World Cultures in Gothenburg, Sweden 2004-.

8. Noordegraaf has written about the concept of script (similar to movie-making) in exhibition design. Noordegraaf 2004.

9. Including the British Museum, V \& A Museum, The Sir John Soane Museum, Pitt Rivers museum etc.

10. See for example Birkett (1989) 2004.

11. On embodied knowledge, see Lakoff \& Johnson 1999.

12. The idea of the white cube is linked to conflicts in museums at the beginning of the 20th century, when the aim was to get rid of the dark displays of the 19th century, with their strict rules about hanging. The definition of the white cube relates to the Museum of Modern Art in New York, where the aim was to create as neutral a background as possible for the works of art. For more on this, see Staniscewski 1998. The gallery space is free of shadows, white, clean, artificial and dedicated to the display techniques of aesthetics. (O’Doherty 1999: 15). However, in the 1970s and 1980s it became clear that even a white cube is not a neutral space. (Corrin 1994: 3-4).

13. For example the British contemporary artists Damien Hirst (b. 1965) has used similar practices as in laboratories as part of his art works. His vitrines with natural history specimens or medical instruments act as something which one can look through and marvel at as something that is removed from every-day life. Also artists Jeff Ko- ons (b. 1955), Susann Hiller (b. 1942) have used the vitrine in order to apply some aspects of laboratory and museum connotations to their artistic work. For example Koon's "New hoover convertible" 1980 or Hillers "From the Freud Museum"1991-996. There are also plenty of other examples; see Turpeinen 2005A: 114.

14. Associations are being made with constant movement, as a hermeneutic circle. From these associations meanings are produced. See also Karjalainen 2004: 208-213.

15. Biggs 2004: 18

\section{LITERATURE}

Aurasmaa, Anne: Salomonin talo. Museon idea renessanssiajattelun valossa. Yliopistopaino. Helsinki 2002.

Biggs, Michael: "Learning from Experience. Approaches to the experimental component of practisebased research", in Karlsson, Henrik (ed.): Forskning. Reflektion. Utveckling. Högskolans konstnärliga institutioner och vägvalet inför framtidet. Rapport frän ett seminarium I Sigtuna Maj 2004. Swedish Research Council. Stockholm 2004.

Birkett, Dea: Spinsters abroad. Victorian Lady Explorers. Sutton Publishing. Thrupp. Stroud. Gloucestershire (1989) 2004.

Böhme, Gernot: "Atmosphere as aesthetic concept". Confurius, Gerrit (Ed.): Constructing athmospheres. Landalos Architecture Art Culture. Berlin 1998, 112-115.

Ceferin, Petra: Constructing a legend. The international Exhibitions of Finnish Architecture 19571967. SKS. Helsinki 2003.

Corrin, Lisa G.: "Mining the museum. Artists look at museums, museums look at themselves" in Corrin, Lisa G. (Ed.): Mining the museum. An installation by Fred Wilson. The Contemporary. 
Baltimore 1994, 1-22.

Corrin, Lisa G.: "A speculative introduction to a speculative exhibition" in Markopoulos, Leigh (Ed.) 2001: GIVE \& TAKE 1 Exhibition 2 Sites. Serpentine Gallery. London 2001, 6-12.

Forgan, Sophie: "The architecture of display: $\mathrm{Mu}$ seums, universities and objects in nineteenthcentury Britain". History of Science Journal. 6/1994, 139-162.

Hooper-Greenhill, Eilean: Museums and the Interpretation of Visual Culture. Routledge. London 2000.

Kalela, Jorma: Historiantutkimus ja historia. Gaudeamus. Helsinki 2000.

Karjalainen, Toni-Matti: Semantic Transformation in Design. Communicating strategic brand identity through product design reference. Taideteollinen korkeakoulu. Helsinki 2004.

Karp, Ivan and Wilson, Fred: "Constructing the spectacle of culture in museums" in Greenberg, Reesa, Ferguson, Bruce W. and Nairne, Sandy (Eds.): Thinking about exhibitions. Routledge. London and New York 1996, 251-267.

Lakoff, George and Johnson, Mark: Philosophy in the Flesh. The embodied mind and its challenge to western thought. Basic Books. New York 1999.

McShine, Kynaston (Ed.): The Museum as Muse. Artists Reflect. The Museum of Modern Art. New York 1999.

Noordegraaf, Julia: Strategies of display. Museum presentation in Nineteenth-and Twentieth-Century Visual Culture. Rotterdam: Museum Boijimans van Beuningen and NAi Publishers 2004.

O'Dorothy, Brian: Inside the white cube. The ideology of the Gallery Space. University of California Press. Los Angeles \& London (1976) 1999.

Peirce, Charles S.: The Essential Peirce: Selected Philosophical Writings, Volume 2. The Peirce Edition Project (Eds.). Indiana University Press. Bloomington IN (1893-1913) 1998.

Putnam, James: Art and the artefact. The museum as medium. Thames \& Hudson. London 2001.

Turpeinen, Outi 2005A: Merkityksellinen museoesine. Kriittinen visuaalisuus kulttuuribistoriallisen museon näyttelysuunnittelussa. University of Art and Design. Helsinki.

Turpeinen, Outi 2005B. Researching the Visual Qualities of Exhibition Design through Experimental and Cross-Disciplinary Methods. In the Making conference proceedings. Copenhagen.

Turpeinen, Outi 2005C: "Researching Visual Qualities of Exhibition Design by Using Experimental and Cross-Disciplinary Methods" in Outi Turpeinen \& Susann Vihma (eds.) (2005): Proceedings from the seminar on Signification, Usability, and Interaction in DESIGN. University of Art and Design. Helsinki.

Vihma, Susann: Products as representation. A semiotic and aesthetic study of design products. Taideteollinen korkeakoulu. Helsinki 1995.

Vihma, Susann: "Ways of interpreting design".

Strandman, Pia (Ed.): No Guru No Method? Discussion on Art and Design Research. University of Art and Design. Helsinki 1998, 7-13.

*Outi Turpeinen DA (Doctor of Arts), researcher, teacher and artist, School of Visual Culture, University of Art and Design, Helsinki, Finland, www.uiah.fil-oturpein

Address: School of Visual Culture, University of Art and Design, Hämeentie 135 C, $00560 \mathrm{Hel}$ sinki, Finland, +358-40-5387079.

E-mail: oturpein@uiah.fi 